\title{
Agrotechnical and energy assessment of strip tillage machine in field conditions
}

\author{
S.G. Mudarisov ${ }^{1}$, H.M. Safin ${ }^{2}$, I.M. Farkhutdinov ${ }^{1, *}$, and R.I. Aminov ${ }^{1}$ \\ ${ }^{1}$ Bashkir State Agrarian University, 450001 Ufa, Russia \\ ${ }^{2}$ Academy of Sciences of the Republic of Bashkortostan, 450008 Ufa, Russia
}

\begin{abstract}
The article presents the results of field studies to determine the quality and energy indicators of a modernized cultivator for strip tillage for industrial crops. An experimental setup with load cells with a nominal value of $30000 \mathrm{~N}$ is designed to measure the tractive resistance of the cultivator in the field. The result of the study is to establish the relationship between the cultivator traction resistance on the speed movement at various angles of spherical disks attack and the degree of crumbling on the structural and technological parameters of the cultivator. Various structural and technological parameters of the cultivator are the basis for measuring hectare fuel consumption.
\end{abstract}

\section{Introduction}

In recent years, conservation technologies in agriculture have been introduced in Russia, as well as around the world. In crop production, such technologies include minimal tillage, non-tillage technology (zero), and strip tillage technology $[1,2]$. Moreover, the technology of strip tillage combines the advantages of minimal tillage and zero technology [3]. Strip tillage by reducing the cultivator impact of the working bodies of machines on soils can reduce not only costs but also increase crop yields $[3,4]$.

The cultivator for strip tillage consists of several sections according to the number of cultivated strips, each section of which is a combination of various working mechanisms - passive and rotational mechanisms. The base of existing cultivator designs is on the following working mechanisms combination: row cleaner, ripper tooth, disc, and packer roller [5]. The quality of soil treatment by cultivators of strip tillage, its traction resistance and, accordingly, the fuel consumption of the tractor largely depend on the design, and technological parameters of the working mechanisms used $[6,7]$.

Lekavičienèa $K$. et al. [6, 7] investigated the influence of the parameters of two elements of the tape tillage equipment - row cleaners and coulters on traction, fuel consumption, and on the movement of straw residues. He found that an increase in the angle of inclination between the disks of the cleaner does not have a significant effect on fuel consumption, while an increase in the speed and depth of penetration of the coulter significantly affects these indicators [7]. The study shows that an increase in the angle of attack of the purifier disks leads to the removal of plant more abundant volume residues from the row [8].
Mark A. Licht and Mahdi Al-Kaisi [8] found that with strip tillage, the temperature of the topsoil increased by $1.2-1.4{ }^{\circ} \mathrm{C}$ compared to the absence of tillage, and it was close to the temperature of chisel tillage. This circumstance is primarily associated with the quality of soil cultivation.

The parameters of the installed discs also affect the quality of soil cultivation and the traction resistance of the strip cultivator. Dedousis [9] found that traction depends on the shape of the disc and speed. An increase in the speed of movement of bulging disks by $0.5 \mathrm{~m} / \mathrm{s}$ increases the traction force by about $30 \%$, while an increase in the speed of movement of flat disks leads to an increase in traction by only $15 \%$.

To further reduce energy consumption and improve the quality of soil cultivation, it is necessary to study the influence of the structural and technological parameters of the working bodies of the strip cultivator on the fuel consumption of the tractor, the traction resistance of the implement and the quality of the crumbling of the soil by the working bodies [10].

The purpose of this study is to determine the influence of the movement speed, the attack angle of round disks, and the depth of travel of cultivators on the traction resistance of the strip cultivator experiments, the degree of soil crumbling and fuel consumption. This study based on processing and analysis of the results of field experiments of a strip cultivator.

\section{Material and methods}

The developed cultivator consists of a frame 1, on which working sections are sequentially installed through a parallelogram mechanism 2 (Fig. 1). Each working section is a combination of sequentially installed working mechanisms: needle discs 3 , cultivator 4 , two

Corresponding author: ildar1702@mail.ru 
parallel mounted flat discs 5, a cultivator with fertilizer ducts for fertilizing 6 , round discs 7 and a planer packer 8 [11].

The agrotechnical assessment program provided the determination of the degree of soil crumbling, the width of the cultivated strip by the cultivator. Soil moisture before cultivation averaged 19-24\%.

Moisture was determined using a moisture meter for bulk materials TR 47122 manufactured by Forli, and the structural state of the soil after the passage of the implement was determined by sieving and separating fractions through sieve frames larger than $100 \mathrm{~mm}$, from 50 to $100 \mathrm{~mm}$, from 25 to $50 \mathrm{~mm}$, from 25 to $10 \mathrm{~mm}$ and less than $10 \mathrm{~mm}$. The degree of crumbling determined as the percentage of fractions less than $10 \mathrm{~mm}$ to the total soil mass.

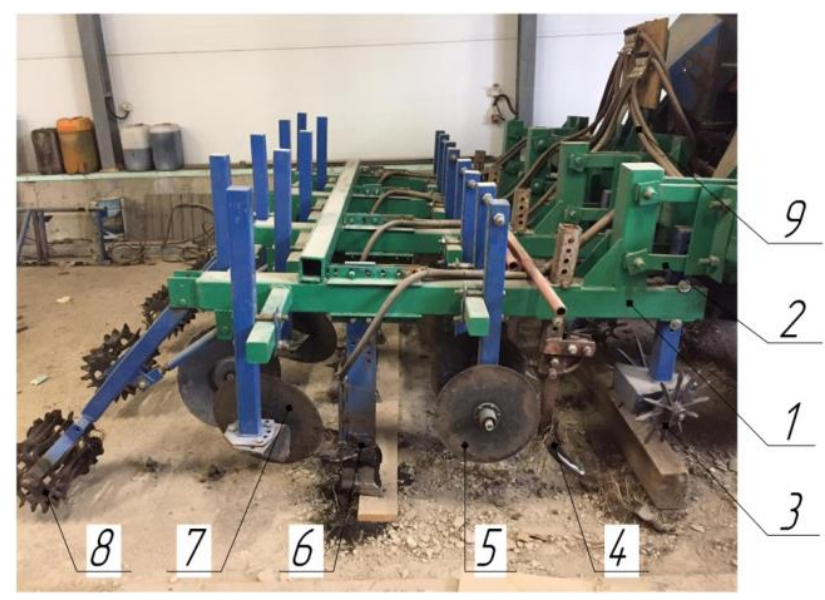

Fig. 1. General view of the cultivator for strip tillage ( 1 - frame; 2 - parallelogram mechanism; 3 - needle discs; 4 - ripper; 5 - flat split discs; 6 - cultivator with fertilizer lines; 7 - spherical wilds; 8 - planar packer roller).

The traction resistance of the cultivator was measured using a MIC - 400 D measuring system using the drag method. At the same time, a tension-link with a sensor with a nominal value of $30,000 \mathrm{~N}$ was used, which was installed between two tractors.

The traction resistance of the cultivator defined as the difference between the total traction resistance and the resistance to the tractor rolling without tools.

A strain gauge sensor was calibrated previously on a calibration stand on a hydraulic bursting machine GRM20. Fig. 2 shows the cultivator during traction resistance measurement. The fuel consumption of the tractor determined by the topping method.

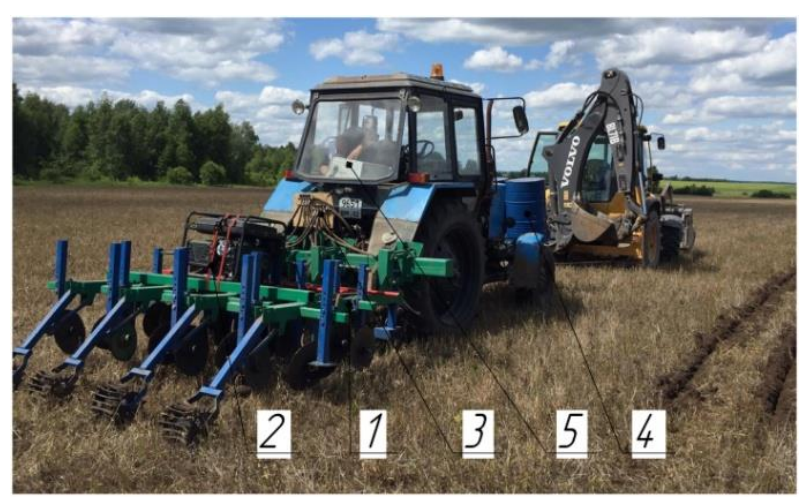

Fig. 2. Unit with device for measuring traction resistance $(1$ - cultivator 2 - power source (gasoline generator); 3 - the supply system of housing and communal services; 4 - capacity for housing and communal services; 5 - measuring complex MIC - 400 D)

\section{Results and discussion}

Both structural and technological parameters of the mechanisms affect the traction resistance of any tillage mechanism. Besides, the physical and mechanical properties of the soil also affect the traction resistance of the cultivator. Preliminary experiments in the field of the developed cultivator section show the ranges of structural and technological parameters at which satisfactory results obtained in terms of quality and energy indicators [11].

During these experiments, it was found that the maximum velocity of the cultivator is $2.5 \mathrm{~m} / \mathrm{s}$. The reason is the observation of soil rejection by spherical disks over the soil tillage band at any angle of attack at high speeds of the cultivator.

There is also a sharp increase in traction resistance of the cultivator at high speeds - the maximum crumbling of the soil achieved at angles of attack of the disks from 25 to 350 . At lower values, the strip is not covered enough with soil, part of the soil remains outside the strip. At large values, the soil is thrown out of the band, although better crumbling is observed [11].

After determining the basic structural and technological parameters of the cultivator section, a fullfledged cultivator was developed, including 4 sections.

For clarifying the structural and technological parameters of the section, field experiments were conducted on a qualitative energy assessment of the cultivator. The results of traction resistance measurement are at a ripper depth of $15-25 \mathrm{~cm}$ and at cultivator speeds of $0.5-2.5 \mathrm{~m} / \mathrm{s}$ (Table 1, Fig. 3-5). 
Table 1. The dependence of the traction resistance of the cultivator depending on the speed and angle of attack of spherical disks

\begin{tabular}{|c|c|c|c|c|c|}
\hline \multirow{2}{*}{$\begin{array}{c}\text { Angle of installation of } \\
\text { spherical disks } \gamma, \\
\text { degree }\end{array}$} & \multicolumn{5}{|c|}{ Implement traction resistance, $\mathrm{N}$} \\
\hline & $\mathrm{V}=0.5 \mathrm{~m} / \mathrm{s}$ & $\mathrm{V}=1 \mathrm{~m} / \mathrm{s}$ & $\mathrm{V}=1.5 \mathrm{~m} / \mathrm{s}$ & $\mathrm{V}=2 \mathrm{~m} / \mathrm{s}$ & $\mathrm{V}=2.5 \mathrm{~m} / \mathrm{s}$ \\
\hline \multicolumn{6}{|c|}{ depth of the cultivator $a=15 \mathrm{~cm}$} \\
\hline$\alpha=20$ degree & 6941.2 & 7412 & 8524.3 & 10254.3 & 12431.5 \\
\hline$\alpha=25$ degree & 7170.1 & 8910.1 & 9710.2 & 10900.1 & 14720.4 \\
\hline$\alpha=30$ degree & 8100.1 & 8900.1 & 10100.3 & 14000.2 & 16942.1 \\
\hline \multicolumn{6}{|c|}{ depth of the cultivator $a=20 \mathrm{~cm}$} \\
\hline$\alpha=20$ degree & 8550.2 & 8701.4 & 10421.5 & 11801.3 & 13456.8 \\
\hline$\alpha=25$ degree & 8803.7 & 9741.3 & 12004.1 & 13871.4 & 16126.4 \\
\hline$\alpha=30$ degree & 9252.4 & 10471.9 & 13002.1 & 14471.2 & 17163.2 \\
\hline \multicolumn{6}{|c|}{ depth of the cultivator $a=25 \mathrm{~cm}$} \\
\hline$\alpha=20$ degree & 9301.2 & 9841.7 & 11900.5 & 12300.2 & 14902.5 \\
\hline$\alpha=25$ degree & 9531.5 & 11751.2 & 12981.2 & 15024.2 & 17200.3 \\
\hline$\alpha=30$ degree & 10874.2 & 12008.1 & 14847.2 & 17850.1 & 19850.4 \\
\hline
\end{tabular}

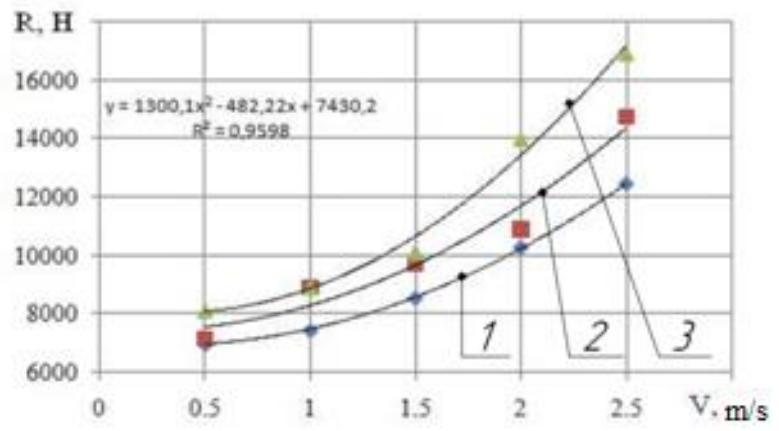

Fig. 3. Traction resistance versus speed for various angles of installation of spherical disks (ripper depth $\mathrm{a}=15 \mathrm{~cm}$ ): $1-\alpha=20$ degree; $2-\alpha=25$ degree; $3-\alpha=30$ degree

The graph shows that with increasing speed, the traction resistance of the cultivator increases (Fig. 3). Moreover, then attack angles of round disks is 200, the increase in traction resistance (depending on speed) is up to $70 \%$, and at an angle of 300 - up to $100 \%$.

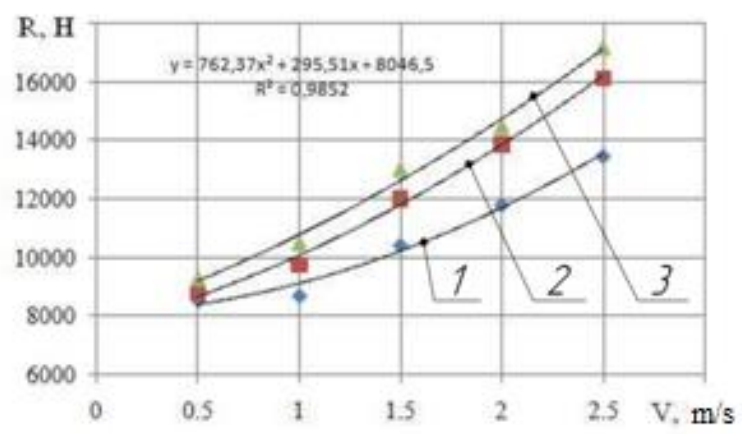

Fig. 4. The dependence of traction resistance on the speed at different angles of installation of spherical disks (depth of the ripper $\mathrm{a}=20 \mathrm{~cm}$ ): $1-\alpha=20$ degree.; $2-\alpha=25$ degree; $3-\alpha=30$ degree

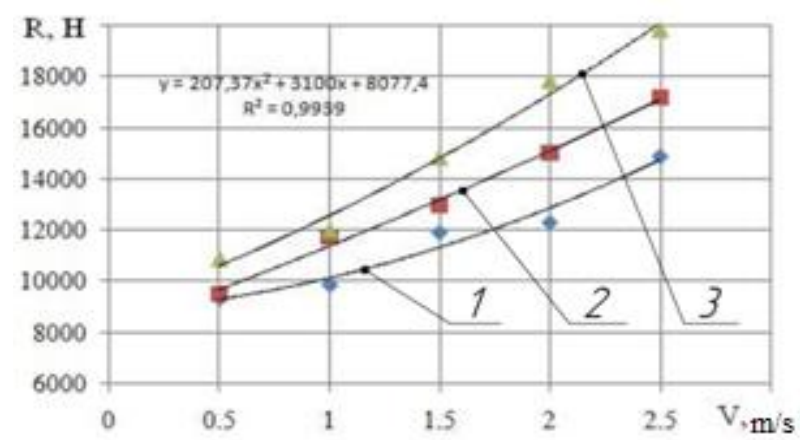

Fig. 5. The dependence of traction resistance on the speed at different angles of installation of spherical disks (depth of the ripper $\mathrm{a}=25 \mathrm{~cm}$ ): $1-\alpha=20$ degree; $2-\alpha=25$ degree; $3-\alpha=30$ degree

The increase in traction resistance is 55-85\% depending on the speed of the unit (Fig. 4).

The increase in traction resistance is 55-80\% depending on the speed of the unit (Fig. 5).

The growth and development of the culture largely depend on the quality of soil preparation, in particular on the quality of crumbling soil. Below are the results of determining the quality of crumbling soil, depending on the structural and technological parameters of the working mechanisms of the developed cultivator and the speed of movement (Table 2).

According to the results, an increase in the speed of the cultivator movement, the quality of crumbling improves. At a speed of $2-2.5 \mathrm{~m} / \mathrm{s}$, soil lumps larger than $100 \mathrm{~mm}$ are absent, while the quality of crumbling is increased by $20-25 \%$. And at a speed of $2.5 \mathrm{~m} / \mathrm{s}$ and a ripper depth of $25 \mathrm{~cm}$, the quality of crumbling is above $90 \%$ and is rated excellently on the scale of quality of crumbling. In the speed range $1.5-2 \mathrm{~m} / \mathrm{s}$, the quality of crumbling is satisfactory. The quality of crumbling is good at a speed of $2.0 \mathrm{~m} / \mathrm{s}$ and a travel depth of $25 \mathrm{~cm}$.

One of the essential characteristics of any mechanism, especially for the consumer, is the fuel 
consumption of the tractor, on which the cost of production depends, among other things [10].

Table 2. The results of assessing the quality of crumbling soil

\begin{tabular}{|c|c|c|c|c|c|c|}
\hline \multirow{2}{*}{$\begin{array}{c}\text { Speed of } \\
\text { movement, } \\
\mathrm{m} / \mathrm{s}\end{array}$} & \multirow{2}{*}{$\begin{array}{c}\text { Ripper } \\
\text { depth, } \\
\mathrm{cm}\end{array}$} & \multicolumn{4}{|c|}{$\begin{array}{l}\text { The amount ( \%) of soil } \\
\text { fractions in size, } \mathrm{mm}\end{array}$} & \multirow[t]{2}{*}{$\begin{array}{l}\text { Degree of } \\
\text { Crumbling }\end{array}$} \\
\hline & & $\begin{array}{l}\stackrel{8}{0} \\
\stackrel{0}{0} \\
\stackrel{\Xi}{\Xi}\end{array}$ & $\begin{array}{l}8 \\
1 \\
8 \\
8\end{array}$ & $\frac{0}{1}$ & 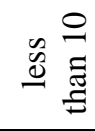 & \\
\hline \multirow{3}{*}{1.5} & 15 & 4.5 & 9.2 & 18.5 & 67.8 & 67.8 \\
\hline & 20 & 4.0 & 9.9 & 12.0 & 74.1 & 74.1 \\
\hline & 25 & 8.8 & 15.2 & 15.6 & 61.4 & 61.4 \\
\hline \multirow{3}{*}{2.0} & 15 & 0 & 8.5 & 15.9 & 75.6 & 75.6 \\
\hline & 20 & 0 & 8.2 & 13.2 & 78.6 & 78.6 \\
\hline & 25 & 0 & 8.7 & 9.5 & 81.8 & 81.8 \\
\hline \multirow{3}{*}{2.5} & 15 & 0 & 5.1 & 10.1 & 84.8 & 84.8 \\
\hline & 20 & 0 & 5.6 & 7.9 & 86.5 & 86.5 \\
\hline & 25 & 0 & 4.5 & 4.3 & 91.2 & 91.2 \\
\hline
\end{tabular}

The study shows fuel consumption measurements for various design and technological parameters of the cultivator (Table 3, Fig. 6).

Table 3. Fuel consumption depending on the speed and angle of attack of spherical disks

\begin{tabular}{|c|c|c|c|c|c|}
\hline \multirow{2}{*}{$\begin{array}{c}\text { Angle of } \\
\text { installation of } \\
\text { spherical disks } \gamma, \\
\text { degree }\end{array}$} & \multicolumn{5}{|c|}{ Fuel consumption liter/ hectare } \\
\hline & $\begin{array}{c}\mathrm{V}=0.5 \\
\mathrm{~m} / \mathrm{s}\end{array}$ & $\begin{array}{l}\mathrm{V}=1 \\
\mathrm{~m} / \mathrm{s}\end{array}$ & $\begin{array}{c}\mathrm{V}=1.5 \\
\mathrm{~m} / \mathrm{s}\end{array}$ & $\begin{array}{l}\mathrm{V}=2 \\
\mathrm{~m} / \mathrm{s}\end{array}$ & $\begin{array}{c}\mathrm{V}=2.5 \\
\mathrm{~m} / \mathrm{s}\end{array}$ \\
\hline$\alpha=20$ degree & 6.2 & 6.9 & 7.6 & 8 & 9.95 \\
\hline$\alpha=25$ degree & 6.6 & 7.3 & 8.4 & 8.9 & 11.5 \\
\hline$\alpha=30$ degree & 6.8 & 8.5 & 9.1 & 9.9 & 12.9 \\
\hline
\end{tabular}

An increase in the speed of movement of the movement leads to an increase in traction resistance of the mechanism and, as a consequence, per hectare fuel consumption. The fuel, on average, increases by $70-80 \%$ in the speed range $0.5-2.5 \mathrm{~m} / \mathrm{s}$ (Fig. 6).

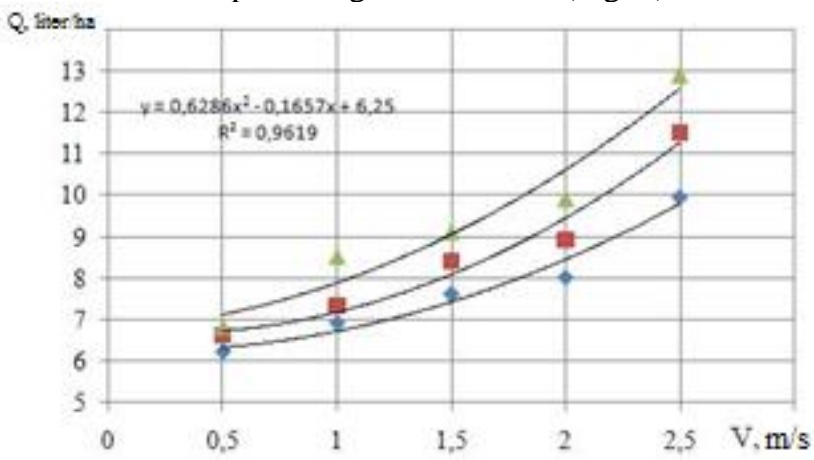

Fig. 6. The dependence of hectare fuel consumption on the speed and angle of attack of spherical disks (depth of the ripper $\mathrm{a}=25 \mathrm{~cm}): 1-\alpha=20$ degree; $2-\alpha=25$ degree;

$3-\alpha=30$ degree

\section{Conclusion}

The study is devoted to experimental verification of the developed cultivator in the field. It was found that the cultivator traction resistance increases with increasing speed, depth of travel of the cultivator, and the angle of attack of the round discs in an exponential manner. The experimental data do not contradict the laws of agricultural mechanics. At angles of attack of round disks of 200, the traction resistance of the cultivator increased by $70 \%$ with an increase in speed from 0.5 to $2.5 \mathrm{~m} / \mathrm{s}$, and at an angle of 300 by $100 \%$ at the same speed range.

The highest degree of crumbling of the soil is observed when the speed of the implement is $2-2.5 \mathrm{~m} / \mathrm{s}$, a further increase in the speed of movement leads to a sharp increase in resistance and the rejection of soil by spherical disks outside the treated strip, which is not allowed by agrotechnical requirements for strip tillage.

Fuel consumption also increases with increasing speed and angle of attack of round disks. An increase in speed from 0.5 to $2.5 \mathrm{~m} / \mathrm{s}$ leads to an increase in fuel consumption by the tractor by $70-80 \%$.

Based on the data obtained, further research is possible to determine the optimal ratio of the structural and technological parameters of the strip cultivator to obtain the required indicators of the quality of soil cultivation with the lowest possible fuel consumption and the highest possible productivity.

\section{References}

1. I. Gabitov, S. Mudarisov, I. Gafurovet et al., Evaluation of the efficiency of mechanized technological processes of agricultural production, J. of Engineer. and Appl. Sci., 13 (Special issue 10), 8338-8345 (2018)

2. D. Laufer, H.J. Koch, Growth and yield formation of sugar beet (Beta vulgaris L.) under strip tillage compared to full width tillage on silt loam soil in Central Europe, Eur. J. Agron., 82, 182-189 (2017)

3. R.G. Evans, W.B. Stevens, W.M. Iversen, Development of strip tillage on sprinkler irrigated sugarbeet, Appl. Eng. Agric., 26, 59-69 (2010)

4. R.P. Wolkowski, Row-placed fertilizer for maize grown with an in-row crop residue management system in southern Wisconsin, Soil Tillage Res., 54, 55-62 (2000)

5. S. Fallahi, M.H. Raoufat, Row-crop planter attachments in a conservation tillage system: a comparative study, Soil Tillage Res., 98, 27-34 (2008)

6. K. Lekavičienėa, E. Šarauskisa, V. Naujokienėa, S. Buragienèa, Z. Kriaučiūnienèb, The effect of the strip tillage machine parameters on the traction force, diesel consumption and $\mathrm{CO}_{2}$ emissions, Soil and Tillage Res., 192, 95-102 (2019)

7. K. Lekavičiene, E. Šarauskis, V. Naujokiene et al., Effect of row cleaner operational settings on crop residue translocation in strip-tillage, Agronomy, 9(5) (2019)

8. M. A. Licht, M. Al-Kaisi, Strip-tillage effect on seedbed soil temperature and other soil physical 
properties, Soil and Tillage Res., 80, 233-249 (2005)

9. A. Dedousis, An investigation into the design of precision weeding mechanisms for inter or intrarow weed control, $\mathrm{PhD}$ dissertation (School of Applied Sciences, Cranfield University, 2007)

10. E. Šarauskis, K. Vaitauskienè, K. Romaneckas, A. Jasinskas, V. Butkus, Z. Kriaučiūnienè, Fuel consumption and $\mathrm{CO}_{2}$ emission analysis in different strip tillage scenarios, Energy, 118, 957-968 (2017)

11. S.G. Mudarisov, R.I. Aminov, I.M. Farkhutdinov, M.M. Yamaletdinov, Working mechanism for fertilizing Strip-Till technology for growing industrial crops, The rural machine operator, 9, 10-11 (2017) 